\title{
Certezas e incertezas na evolução do pensamento
}

\section{Certainties and Uncertainties in the evolution of thought}

\section{Eurípedes Falcão Vieira'}

\section{Resumo}

Este ensaio penetra o mundo das certezas e incertezas no âmbito de estruturações cognitivas, onde se elaboram as formulações teóricas do pensamento. O processo de criação do conhecimento percorreu um longo caminho, identificado com a evolução da capacidade de desenvolvimento da mente humana. Nesse processo foram estabelecidas certezas e incertezas no modo de entendimento da razão existencial.

Pala vras chaves: certezas, incertezas, estruturascognitivas.

\section{Abstract}

This essay enters the world of certainty and uncertainty concerning cognitive structuring, where theoretical formulations of thought are elaborated. The process of knowledge creation has come a long way, identified with the evolution of the capacity of human's mind development. In this process, certainty and uncertainty were established in the way of understanding the reason of existence.

Key words: certainty, uncertainty, cognitive structuring.

\section{Introdução}

A formação das estruturas mentais é remissiva aos primórdios da evolução da espécie humana. É um tempo imemorial no qual o sentido da evolução começa a delinear o tipo humano semi-ereto. Uma longa decorrência de especificidades tempo-espaço induziria a evolução ao posicionamento ereto, favorecendo o desenvolvimento da capacidade de observação, reflexão e raciocínio. É a introdução ao pensamento. A racionalidade humana agregou progressivamente novos valores no cenário restrito dos ambientes nos quais os diversos segmentos da espécie humana se desenvolviam. O homem sapiente abre as primeiras janelas do conhecimento. As conexões neurais do pensamento primitivo se estabeleceriam e evoluiriam a partir de percepções recolhidas na visão transitiva do mundo de reações instintivas imediatas à sobrevivência e o mundo da racionalidade em evolução lenta e progressiva.

Há uma indeterminação temporal para o momento de ruptura da configuração mental primitiva que afastou o homem da condição irracional, comum e identificada na convivência ambiental com os demais seres. Esse descolamento de origem foi crucial ao desenvolvimento do pensamento. Recolhendo dados das práticas empíricas, produzindo informação e conhecimento, a mente humana foi desencadeando e ativandb, continuamente, novas conexões neurônicas.

O componente social iniciado pelos agrupamentos primitivos teve, também, importância relevante para o estabelecimento de relações familiares e pessoais. As relações entre grupos se seguiriam com as dificuldades impostas pela amplidão dos espaços, além das desconfianças e disputas naturais. Contudo, elas permitiriam, em sequiência, aproximações que resultariam em conformações sociais, prenúncio de futuras sociedades e

\footnotetext{
1 Doutor em Geografia pela Universidad Del Salvador, Buenos Aires e Bacharel em Ciências Políticas e Econômicas pela Fundação Universidade Federal do Rio Grande (RS); Membro do Instituto Histórico e Geográfico do Rio Grande do Sul. Endereço: Rua Gonçalves Dias, 170 - apt. 602 - Menino Deus - Porto Alegre/RS CEP 90130-060 -Brasil.E-mail:euripedesfalcao@terra.com.br 
civilizações. As identidades, na configuração dos agrupamentos no tempo-espaço primitivo, caracterizariam a distinção étnica que se prolongaria e perpassaria épocas ao longo dos diversos processos civilizatórios.

O homem sapiente é um dos fenômenos naturais mais bem sucedidos na visão holística da vida no planeta. A capacidade de desenvolver o pensamento por meio de intrincada rede de células nervosas, cujos comandos estão nas percepções extemas, ainda hoje, mesmo com os avanços da neurociência, é um mundo por desvendar. O cérebro é um sistema físico-químico numa estrutura biológica, passível de impulsos a partir dos sentidos. Assim são modeladas as ações e reações, algumas com forte identidade entre os seres vivos, como o instinto de sobrevivência, a defesa da vida e a replicação. Porém, na espécie humana a evolução criaria um novo fat or, a capacidade de recolher dados, armazená-los e processá-los, produzindo, dessa forma uma nova capacitação, a de pensar.

A capacidade de pensar estabeleceu o diferencial e o desequilíbrio no mundo da existência viva da Terra. Ela ia além dos três pilares fundamentais de identidade entre os seres vivos. Pensar deu ao homem a possibilidade de impor-se como ser superior na escala animal. As relações com os objetos da vida e da natureza deixam de ser apenas ontológicas para, gradativamente, se tomarem epistemológicas. Essa passagem está na origem da observação e da experiment ação.

O passar dos anos, a estrutura cognitiva humana acumulou observações e experimentações, capazes de gerar especulação sobre fenômenos ainda não entendidos adequadamente. As hipóteses e a formulação de teorias descortinam a grandeza da mente humana. A hipótese sobre um fenômeno é uma suposição sobre a qual se sistematiza um conjunto de idéias, a dar origem a uma formulação teórica. Como se trata de uma especulação no campo científico, a teoria é sempre uma incerteza. Mesmo comprovada pela experimentação, ela pode ter alterado o seu sentido, dependendo da interpret ação tirada de suas próprias potencialidades. Assim o que parece ser uma certeza contém, no conjunto de variáveis inerentes, a incerteza.

Os fenômenos naturais se manifestam em forma de sistemas conectados. A conformação sistêmica dos eventos de natureza física repercute e modela os eventos de natureza biológica. Há interação, cumplicidade e dependência. Mudança, adaptação, evolução são conseqüência do estado dinâmico das forças atuantes no sistema energético-material do tempo-espaço na dimensão cósmica. Na natureza terrestre e na natureza do universo é o que entendemos no atual estágio do conhecimento. Em ambas as naturezas o que temos, portanto, são estados dinâmicos, de mudança constante. As mudanças no conhecimento adquirido se processam pela dialética do pensamento crítico. Assim as certezas de momento vão se transformando continuamente, produzindo incertezas no entendimento dos fenômenos naturais e sociais.

O pensamento crítico fundamentou as bases para o processo do conhecimento. Sem ele a dinâmica da capacidade de pensar e formular novas idéias configuraria um campo de inércia cognitiva, criando uma impossibilidade lógica de evolução do conhecimento. A mente humana ficaria refém da inflexibilidade criativa. A perspectiva proativa do pensamento crítico, no entanto, abriu as fronteiras do pensamento, produziu estímulos neurônicos e elevou a mente humana a uma etapa superior, capaz de formular cont inuamente novas hipóteses e elaborar novas teorias.

A capacidade criativa da mente humana formou um processo cumulativo de conhecimentos, desenvolveu a atitude inovadora na ciência e na tecnologia. Em decorrências de tempo cada vez mais curtas - domínio do tempo curto - a geração de conhecimento científico e tecnológico configurou uma orla de tempo, transitivo, a modelar a presente atualidade. A inovação e a mudança são parte do tempo mais imediato, condicionando o ser social ao um estado de constante incerteza.

No campo social, e particularmente, na presente modemidade, nada permanece por muito tempo. A transit ividade vai se const ituindo um paradigma-signo da nova modernidade. O conhecimento e a informação chegam rapidamente, em tempo real, na compressão do tempo-espaço. No mundo das objetividades e subjetividades globais os comportamentos individuais e coletivos convergem e divergem nas cenas do cotidiano.

A organização social, a econômica e a cultural na qual o sujeit o se vê envolvido e dominado, pode não ser o seu mundo ideal, mas dele não pode fugir, e nele tem de realizar sua representação como ser social, ainda que de 
forma discordante. O conflito é inevitável. Suas certezas pessoais se chocam frontalmente com as incertezas da época. Procurando um foco de adaptação, o sujeito fragiliza suas posições pessoais, sendo arrastado pela imponderabilidade da incerteza. Ao longo de uma mesma existência diversas realidades vão sendo vivenciadas, induzidas pela mudança semiológica, pela natureza dos novos significados, principalmente, os introduzidos pela alta tecnologia. Sentir o momento da mudança e a necessidade de desenvolver novas capacitações é uma condição crucial de existência. As novas capacitações fazem parte do potencial da mente humana para a adaptação e inovações do conhecimento.

\section{Estrutura cognitiva e realidade}

Em cada época o homem desenvolveu uma estrutura cognitiva em relação à realidade natural e social. Essa capacidade permite estabelecer relações com a natureza e condicionamentos às normas de funcionamento da sociedade. A mente humana não se mantém em inércia cognitiva, embora pressionada e condicionada por costumes, crenças e ideologias de época. Ainda que não expressas, a dinâmica das idéias acaba por forçar as molduras que as aprisionam, manifestando-se sob a forma de protestos, teorias e novos conhecimentos.

As estrut uras cognitivas têm se alterado ao longo dos anos. Em algumas sociedades dominam por maiortempo, em outras se alteram mais rapidamente, de acordo com o processo inato à inovação e à mudança. Se o domínio cognitivo é muito longo, por exemplo, os quatro séculos de idade média, há uma substancial perda no tempoespaço para o processo de inovação e mudança. A sociedade se atrasa em fundamentações ideológicas e teológicas, particularmente. Tomando os últimos 10.000 anos de evolução do pensamento e da geração do conhecimento, colocam-se duas suposições importantes: 1) a sociedade com os condicionamentos referidos; e 2) a sociedade sem eles. No primeiro caso, a época at ual mostra o nível e o desnível de conhecimento, cultura e saber científico, ou seja, sociedades avançadas, médias e atrasadas, a partir do maior ou menor domínio ideológico e teológico nelas introduzidos. No segundo caso, seria uma situação ideal, sem tais impactos e, por conseqüência, seria alcançada uma et apa mais avançada do conhecimento.

Estruturas mentais se formam e evoluem de acordo com a maior ou menor liberdade de pensamento e expressão, a contraposição de idéias, a formulação de hipóteses e a elaboração de teorias. Assim se amplia o campo mental a partir da capacidade de observação e experimentação. A observação, a formulação e a experimentação são os requisitos básicos para o entendimento da realidade, num dado momento do processo de desenvolvimento da civilização. Observar os fenômenos nat urais e os eventos sociais e sobre eles formular uma hipótese de entendimento, sustentá-la pelo desenvolvimento de teorias físicas e socioculturais induz à experimentação e comprovação de sua validade ou não.

O que conhecemos hoje sobre os fenômenos naturais é o produto do conhecimento gerado, não raro, no confronto de idéias. A ruptura de grandes certezas impostas dogmaticamente, ou resultantes da evolução epistemológica do pensamento, assegurou avanços no campo do conhecimento. A teoria geocêntrica, a teoria heliocêntrica, a teoria das órbitas elípticas, a teoria da mecânica celeste, a teoria da evolução das espécies, a teoria quântica e a teoria da relatividade foram etapas decisivas do pensamento para se alcançar o conhecimento científico avançado e o aparato tecnológico atual. Essas três últimas teorias mudaram exponencialmente a compreensão da realidade, criando novos padrões tecnológicos que puseram fim ao longo período da era industrial no final do século XX. A geração das tecnologias microeletrônicas introduziu a modernidade cibernética, uma transformação profunda nos meios de produção, nas relações sociais, culturais e nos comportamentos. Ainda mais, essas teorias fundamentaram as novas relações do homem com natureza, com a organização social da qual faz parte e, igualmente, dele com ele próprio. O homem em busca de seus próprios mistérios!

Ao tentar desvendar a natureza quântica do cérebro o homem procura, compreender as complexas reações físico-químicas processadas, impulsionadas pelos sentidos. À estrutura biológica em evolução, amparada em características antecedentes, transmitidas no processo de replicação, somam-se características adquiridas nos modelos sociais, criando identidades pessoais e formas de comportamento em cada época. 


\section{Soma conceitual}

A mente humana elabora níveis contextuais de objetividades e subjetividades na ordem temporal dos processos de desenvolvimento. O poder de reflexão, principalmente, quando associado à aquisição de conhecimentos, às identidades individuais e coletivas, à construção cultural foram, nos diversos encaminhamentos às diferentes modernidades, variáveis importantes à reflexão e à inflexão das idéias. As conformações espaciais limitaram o poder de reflexão e a construção do pensamento a imagens representativas do mundo dos objetos mais imediatos. A mobilidade e o desenvolvimento da racionalidade cognitivo-instrumental foram alargando, progressivamente, a capacidade de reflexão a partir da ampliação dos horizontes de observação. Abriu-se, por outro lado, a possibilidade de subjetivações, elaboração de proposições abstratas como um corolário do real.

O limite de observação da mente por meio dos sentidos é extremamente pequeno. Há o mundo do infinitamente grande e o mundo do infinitamente pequeno; ambos não observáveis diretamente. A racionalidade instrumental, a soma de ciência e tecnologia, vem permitindo novos horizontes à observação dos objetos do mundo real e permitindo, pela formulação de hipóteses e teorias, numa teia de abstrações o encontro do entendimento e da compreensão do funcionamento sistêmico do mundo real.

Essa tentativa de compreensão é, na verdade, um nascedouro de incertezas. Somam-se, por vezes, certezas momentâneas como se configurassem uma soma matemática: uma certeza mais outra certeza produzem duas certezas. Assim, $n$ certezas somariam $n$ certezas. Tomando-se um arco de tempo-espaço histórico, a idade média, por exemplo, obtém-se a imagem de um mundo de certezas ideológicas e teológicas a projetar a sociedade simbólica dos tempos futuros. A sociedade seria o espelho do conformismo cognitivo irredutível, reducionista e condicionante, a um só tempo; cenário de subjetivações e abstrações da representação do mundo real pela superposição de um mundo sobre-real.

Em todas as épocas, porém, emergiu a inflexão, um desvio ao pensamento dominante, estabelecendo o princípio fundamental da contraposição de idéias. As cert ezas sempre foram cont estadas, mas o aparelhamento social de presumíveis verdades absolutas, em determinadas épocas e sociedades, dominou as mentes por tempos diferentes, conforme a maior ou menor liberdade de pensar e exprimir idéias. Contudo, mesmo em contextos dogmáticos, algumas certezas caíram com a formulação de novas teorias, abrindb, assim, caminho para novas fronteiras do conhecimento.

Conceitualmente, a soma de duas certezas produz uma incerteza, conseqüentemente, a soma de $n$ certezas irá produzir $n$ incertezas.

A representação gráfica mostra que a partir de uma certeza gera-se uma incerteza que ativa a especulação cognitiva, ou seja, a busca de novas formas de conhecimento. A formulação sucessiva de hipóteses e teorias estabelece as bases para o conhecimento avançado em determinada modernidade.

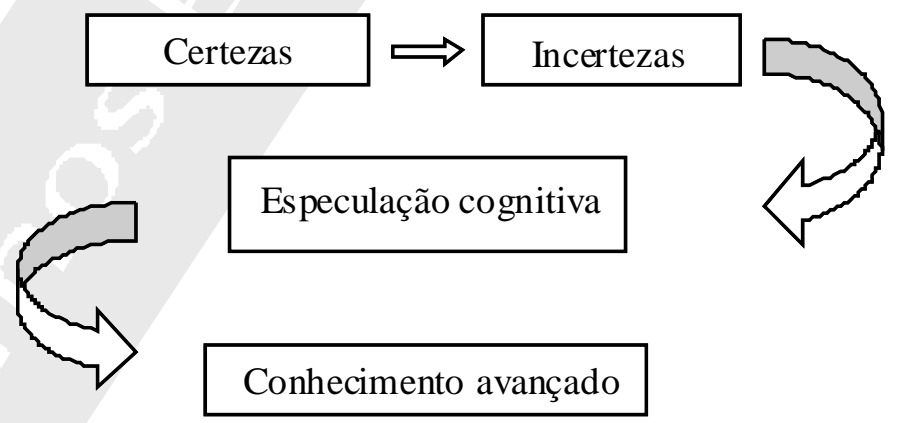

Como o conhecimento se tornou um processo cumulativo tende, sempre, ao aceleramento à medida que se desenvolve a capacidade especulativa da mente humana. Há como um inconformismo lógico - atributo da mente - diante da visão dos fenômenos naturais e sociais. Isso produz um efeito especulativo permanente no campo da ciência e da tecnologia.

A especulação cognitiva contrapõe-se ao conformismo cognitivo. Dependendo do estágio de desenvolvimento e dos condicionamentos impostos pelos costumes, crenças, dominações e isolamento, grupos antropológicos 
submeteram-se, em maior ou menor grau, ao conformismo cognitivo. Formou-se, assim, um processo civilizacional pouco dinâmico, perpassando os séculos sem avanços significativos na construção do conhecimento.

Por outro lado, em situações de intensos inter-relacionamentos, aperfeiçoamento lingüístico, consciência mais ampla da realidade nat ural e características étnicas, determinados grupos humanos concentram poder e visão mental capaz de dinamizar o processo do conhecimento. Há ainda, a considerar, influências do meio natural e os relacionamentos que se estabeleceram em ambientes de características naturais muito específicas.

Um dinamismo antropológico aberto, nos grupos de maior mobilidade espacial e cultural, a especulação cognitiva se desenvolveu mais intensamente. Os grupos étnicos que se mantiveram intactos, no perpassar dos anos, favoreceram os aperfeiçoamentos genéticos, tornando-os mais aptos à qualificação do pensamento e, conseqüentemente, at ingindo os níveis mais elevados do conhecimento. A herança genética não é uma variável a ser desprezada. Preconceitos, muitas vezes, dificultam, mutilam ou atrasam os desenvolvimentos culturais, artísticos e científicos.

A presente modernidade sintetiza e ao mesmo tempo amplia os conhecimentos. Soma as conquistas, sem, contudo, tomá-las verdades absolutas. Sobre o que no passado foi construído, formulam-se novas hipóteses e teorias, como um intervalar de incertezas epistemológicas, abrindo, desta forma, novas fronteiras para o entendimento dos fenômenos sociais e naturais. Esse é um caminho sem volta, uma cogitação de futuro a não ser detida. As questões éticas, muitas vezes levantadas, também estão sujeitas a mudanças, aperfeiçoamentos nos princípios gerais que induzem aos comportamentos morais. Tudo acaba por se harmonizar, ética, crença, comportamento; é o triunfo da inteligência humana!

As desigual dades sociais, culturais, técnicas e científicas no tempo-rítmico do desenvolvimento, no interior de cada país, em cada continente, ilhas ou em escala global deve se analisado em particularidades próprias. Nenhuma formação civilizacional é igual à outra. A natureza genética, o meio natural, os relacionamentos, a lingüística são fatores essenciais. As crenças, a ética religiosa, os códigos de costumes, tábuas de leis, a atitude, enfim, a inércia ou a dinâmica tornam-se a razão substantiva e dialética no processo de evolução das sociedades.

Na atualidade, passados mais de 10.000 anos de evolução do homo sapiens, convivem sociedades de conhecimento avançado com formas ainda tribais de organização social. Umas evoluíram pela mudança, pela forte at ivação das tensões neurais, outras, porém, permaneceram inertes, presas a estruturas mentais do passado. Há uma razão antropológica para isso ancorada na capacidade de uns e incapacidade de outros de desenvolverem a estrutura mental.

É na ancestralidade humana que está parte da resposta. Ancestralidade mais evoluída e ancestralidade menos evoluída. O tempo-espaço foi fundamental. Grupos primitivos antecederam a outros, com desenvolvimento genético mais apurado em função das condições ambientais. Traços étnicos particularizados e suas relações com as condições ambientais e os recursos disponíveis permitiram estabelecer condições de vida e evolução diferenciadas.

A sociedade atual, numa visão holística, mostra segmentos extremamente diferenciados. Contudo, o acesso ao conhecimento e à informação tem favorecido os treinamentos das mentes, o que possibilita saltos qualitativos em termos de estruturas cognitivas. Os que deixam suas sociedades arcaicas para adquirem formação nos centros mais avançados do conhecimento, o ret orno às origens pode significar uma cunha para remover o atraso histórico. Às certezas dominantes, um novo ideário vai ganhando espaço e as incertezas vão abrindo caminho a formas inovadoras do pensamento.

Sempre que as tradições deixam de ser vivenciadas e passam a ser, apenas, cultivadas, as possibilidades de desenvolvimento se aceleram. A revolução educacional, a especulação científica e a geração de tecnologia promovem rupturas epistemológicas e pragmáticas transformando, em curtas decorrências de tempo, sociedades fechadas milenarmente em sociedades abertas, modernas e de elevados níveis de desenvolvimento. 
O impulso humano à inovação, à mudança é, na verdade, a emergência de energias a atividades capazes de satisfazer as inquietudes pessoais e sociais. Cada pessoa tem um potencial energético para desenvolver uma forma de atividade. Quando esse potencial energético atinge níveis superiores na estrutura cognitiva há manifestações de genialidade. $\mathrm{O}$ avanço da ciência, as manifestações artísticas na pintura, na música e na literatura são produtos de uma razão mental de alto poder nos enlaces neurônicos.

Os confrontos certezas e incertezas dominam o pensamento humano ao longo dos anos. O século XXI trás a marca de um tempo de incertezas. A velocidade do avanço científico e tecnológico, o poder das comunicações em tempo real, os novos horizontes observáveis no macro e micro universos não guardam lugar para certezas. Tudo pode mudar rapidamente, conceitual e pragmaticamente. Nas organizações de produção, de serviços, nas manifestações culturais e na formação de elites intelectuais globalizadas os processos de mudança, aperfeiçoamento e inovação são praticamente contínuos. Num quadro real, portanto, a soma das certezas presumidas produz sempre uma razão de incerteza.

\section{Conclusão}

Este ensaio é, na verdade, uma grande incerteza. A incerteza da realidade, a incerteza da vida e a incerteza do futuro. Mas é por esse caminho que tem evoluído a sociedade humana. Não como uma totalidade, mas pelos fragmentos civilizatórios que venceram, em períodos intervalares, as certezas estabelecidas.

Num intervalo muito pequeno, apenas, duas décadas, houve uma mudança radical de ambiente a ser vivenciado. As gerações que estão chegando encontram um mundo de tecnologias, conhecimentos e possibilidades imediatas desconhecidas das gerações da última metade do século XX. Coisas recentes, de poucos anos, tomam-se, rapidamente, passado. As perspectivas de vida fundamentam-se, permanentemente, no futuro das incertezas.

Essa nova realidade induz os que se mantém na ativa da vida produtiva a terem, constantemente, de buscar formas de atualização, pois atransitividade torna-se uma realidade de curto prazo. Os avanços do conhecimento estão cada vez mais vinculados ao conteúdo e aos meios de transporte via diversificação e aprimoramento tecnológico.

Conciliar as gerações nos momentos de mudança em tempo curto exige comportamentos que deixem para trás, rapidamente, sucessões de narrativas de vida ancoradas em condições histórico-estruturais de tempo longo. Na América Latina, particularmente, o enraizamento de práticas histórico-estruturais, têm dificuldade a mudança, em amplitude continental. Embora se devam considerar particularidades regionais, em escala de rompimento com o passado colonialista e feudal, práticas ainda hoje presentes em regiões brasileiras e muito transparentes nos costumes políticos, deixam claras as deficiências históricas, como por exemplo, no campo da educação e da formação política.

O Brasil, bem como os demais países latino-americanos, levando em conta as diferentes latinidades ao sul do Rio Grande (Bravo) precisam romper com o sistema educacional de certezas no plano discursivo e de natureza informativa no plano pedagógico. Assim, passará, definitivamente, por ruptura, ao plano das incertezas analíticas, com ganhos efetivos em inserção nas geoestratégias globais, não só pela inteligência global como em produtos de valor agregado. Do contrário ficará, sempre, como uma utopia a ser realizada.

O que a América Latina deixou de fazer nos últimos 30 anos, a Ásia o fez e os resultados são inquestionáveis. A preparação adequada das novas gerações produziu uma massa crítica de técnicos de alto nível que rompeu com as certezas do passado e lançou as bases para a mudança, a transformação, enfim, para uma sociedade de conhecimento avançado.

Certezas e incertezas, um dos dilemas epistemológicos ao rompimento das barreiras histórico-estruturais para o desenvolvimento e evolução do pensamento! 